\title{
Estrutura Entoacional de Sentenças Neutras em Português Brasileiro na variedade de Minas Gerais
}

\section{Intonational Structure of neutral sentences in Brazilian Portuguese in the variety from Minas Gerais state}

\author{
Priscila Marques Toneli* \\ Universidade Estadual de Campinas, Campinas, SP, Brasil \\ Maria Bernadete Marques Abaurre* \\ Universidade Estadual de Campinas, Campinas, SP, Brasil \\ Marina Vigário ${ }^{* * *}$ \\ Universidade de Lisboa, Lisboa, Portugal
}

\begin{abstract}
Resumo: $O$ presente trabalho analisa a estrutura entoacional de sentenças declarativas neutras na variedade de Minas Gerais do Português Brasileiro (PB), destacando a influência do número de sílabas em palavra prosódica (PW) e a importância do grupo de palavra prosódica (PWG) para a distribuição de acentos tonais. Foram analisados dados da variedade mineira, falada no Triângulo Mineiro, os quais foram obtidos de modo controlado experimentalmente e analisados com base nos modelos teóricos da Fonologia Prosódica e Entoacional (Beckman; Pierrehumbert, 1986; Ladd, 1996, 2008; Selkirk, 1982, 1984, 1986; Nespor e Vogel, 1986). Os resultados apresentados e analisados estatisticamente mostram que há associação praticamente categórica de um acento tonal a cada $\operatorname{PW}(G)$ no interior da sentença. A análise mostrou que o número de sílabas das PWs em interior de sentença também desempenha um papel relevante na alta densidade tonal na variedade analisada, assim como na variedade paulista, tal como mostrado em Vigário e Fernandes-Svartman (2010) e Fernandes-Svartman e Romano (2017).
\end{abstract}

Palavras-chave: Português brasileiro. Entoação. Associação Tonal.

\begin{abstract}
This paper analyses the intonational structure of neutral declarative sentences of Brazilian Portuguese (BP) variety from Minas Gerais state, highlighting the influence of the number of syllables within prosodic words (PW), as well as of the prosodic word group (PWG) for the distribution of pitch accents (PAs). We analysed data from the variety of Minas Gerais, spoken in the Triângulo Mineiro, which was obtained in an experimentally controlled way, and analysed within the models of prosodic phonology and intonational phonology (Beckman; Pierrehumbert, 1986; Ladd, 1996, 2008; Selkirk, 1982, 1984, 1986; Nespor and Vogel, 1986). The results presented and analysed statistically show that the association of $\mathrm{PA}$ at the level of $\mathrm{PW}(\mathrm{G})$ in the internal position of the sentence is almost categorical. The analysis also showed that the number of
\end{abstract}

Pesquisadora colaboradora do Departamento de Linguística do Instituto de Estudos da Linguagem da Universidade Estadual de Campinas, Campinas, SP, Brasil; pmtoneli@gmail.com

** Professora titular do Departamento de Linguística do Instituto de Estudos da Linguagem da Universidade Estadual de Campinas, Campinas, SP, Brasil; bernadete.abaurre@gmail.com

*** Professora associada no Departamento de Linguística da Faculdade de Letras da Universidade de Lisboa; marina.vigario@mail.telepac.pt 
syllables of PWs also play a relevant role in the high tonal density in this variety of BP, patterning similarly to the variety spoken in São Paulo state, as described in Vigário and Fernandes-Svartman (2010) and Fernandes-Svartman and Romano (2017).

Key-words: Brazilian Portuguese. Intonation. Tonal Association.

\section{INTRODUÇÃo}

Neste artigo, descreveremos e analisaremos dados de fala controlada referentes à estrutura entoacional de sentenças declarativas produzidas em contexto de foco amplo (sentenças neutras). Nosso objetivo central era observar a distribuição tonal na posição interna da sentença ${ }^{1}$, correspondente a um único sintagma entoacional, posição essa que inclui o verbo e um objeto ou um adjunto adverbial. Nossa análise destaca apenas o sintagma pós-verbal subsequente ao verbo em uma variedade de Português Brasileiro (PB), mais especificamente a variedade falada no Triângulo Mineiro, região do estado de Minas Gerais (MG). Essa variedade é a analisada em Toneli (2014).

$\mathrm{Na}$ literatura sobre o $\mathrm{PB}$, não há ainda convergência quanto ao domínio relevante para a distribuição tonal em sentenças neutras. Os trabalhos de Frota e Vigário (2000) e Tenani (2002) chamam a atenção para o fato de o domínio de associação tonal no PB ser claramente mais baixo do que no Português Europeu (PE). A partir dos dados ali analisados, integrando fundamentalmente sintagmas fonológicos compostos por uma palavra prosódica (prosodic word - PW), estas autoras defendem que o domínio relevante é a frase fonológica $(\phi)$.

Pesquisas subsequentes, como as de Fernandes (2007) e Tenani e FernandesSvartman (2008), indicam que, para o mesmo tipo de sentença do PB, é a PW o domínio mínimo considerado para a associação dos acentos tonais (pitch accents - PA).

Nos vários estudos, há coincidência sistemática entre PW e o Grupo de Palavra Prosódica (Prosodic Word Group - PWG), proposto por Vigário (2007, 2010). De acordo com Vigário, o PWG é um domínio prosódico autônomo entre PW e $\phi$, que corresponde essencialmente a uma palavra sintática e que pode incluir uma única PW (e.g. borboleta) ou duas ou mais PWs, como no caso por exemplo das palavras compostas por reanálise (e.g. luso-brasileiro). Com vista a determinar qual nível obriga à presença de um acento tonal, PW ou PWG, Vigário e Fernandes-Svartman (2010) investigam a distribuição tonal em PWG ramificados (e.g. guarda-costas) e PWG não ramificados (e.g. engana), concluindo que os acentos tonais são (praticamente) obrigatórios em cabeças de PWG e opcionais em não cabeças, sendo neste caso relevante o tamanho das PW no interior de PWG. Por fim, Toneli (2014), ao analisar tanto PWG ramificado quanto o não ramificado, defende, a partir de análises estatísticas, a relevância do domínio PW para a aplicação de tal regra entoacional.

\footnotetext{
${ }^{1}$ Destacamos que não é nosso intuito fazer uma análise sintática desta posição, pois o corpus não foi elaborado e controlado para tal verificação. Quando as sentenças foram construídas, foram levados em consideração fatores como o número de sílabas em PW, o tipo de domínio prosódico a ser analisado (PW, PWG e $\phi$ ), a configuração morfológica dos elementos, sejam palavras funcionais ou lexicais, e a posição interna para evitar influências das fronteiras de I na distribuição dos acentos tonais.
} 
Fernandes-Svartman e Romano (2017) destacam que, apesar de haver pontos discordantes entre os trabalhos mencionados acima, em todos são apresentados indícios de que o número de sílabas que antecedem o acento principal de $\phi$ e a ramificação sintática e prosódica dos constituintes influenciam a associação de acentos tonais às sentenças neutras do PB. Além de atestar a relevância desses fatores para a distribuição tonal em sentenças neutras no PB, os autores corroboram em sua análise a hipótese já pesquisada em Fernandes (2007), Tenani e Fernandes-Svartman (2008) e Toneli (2014), a qual defende que a associação tonal toma como domínio de aplicação a PW. É importante destacar que, se bem que Vigário e FernandesSvartman (2010) e Toneli (2014) compararam a distribuição tonal em sentenças que incluem PWG ramificado e não ramificado, também Fernandes-Svartman e Romano (2017) não distinguiam PW e PWG não ramificado, o que pode gerar um ruído na defesa de que é PW e não PWG o domínio relevante para a distribuição tonal.

Em vista disso, nosso objetivo é mostrar que fenômenos entoacionais como a atribuição de PAs e de acento inicial de PW também na variedade mineira têm como domínio mínimo PW(G), tal como mostrado para a variedade paulista em trabalhos anteriores, como Fernandes (2007), Tenani e Fernandes-Svartman (2008), Vigário e Fernandes-Svartman (2010), Toneli (2014), Fernandes-Svartman e Romano (2017). Argumentaremos ainda que, complementando o que trabalhos anteriores já apontaram para a variedade paulista, o número de sílabas e a ramificação prosódica são fatores determinantes na associação tonal em sentenças neutras na variedade mineira quando as palavras em análise estão na posição interna de I.

Com base nessa explanação inicial e para amparar nossa análise, na seção 2, faremos uma breve exposição do quadro teórico a ser utilizado e de outros trabalhos que analisam a estrutura entoacional em outras variedades do $\mathrm{PB}$, dando destaque àqueles que exploram a relevância de PW para a distribuição tonal. $\mathrm{Na}$ seção 3, descrevemos o experimento realizado com sentenças declarativas produzidas em contexto de foco de escopo amplo - sentenças neutras -, destacando que nossa análise incidirá nos elementos internos à frase que seguem imediatamente o verbo, com o intuito de evitar influências de fronteira de sintagma entoacional.

Posteriormente, na seção 4, apresentamos e analisamos os resultados para as sentenças que incluem os elementos em análise, argumentando que o número de sílabas em PW aumenta a probabilidade de ocorrência de acento inicial de PW e de PA associado à não cabeça de PWG ramificado. Além disso, nossa análise será validada com testes estatísticos, realizados no programa $\mathrm{R}$ (versão 3.0.2), para justificar que a distribuição de PAs toma PWG e PW como domínios relevantes para a associação tonal no $\mathrm{PB}$ (há coincidência grande entre eles em grande parte dos dados), com associação tonal obrigatória de PA à PW cabeça de PWG ramificado e uma fortíssima probabilidade de associação tonal à PW não cabeça em função do número de sílabas de PWG. Por fim, finalizamos o artigo explicitando nossas contribuições e as considerações finais.

\section{QUADRO TEÓRICO}

$\mathrm{Na}$ presente seção, apresentaremos os pressupostos teóricos basilares que nortearam a análise dos dados de fala, no quadro da Fonologia Prosódica (Selkirk, 1982, 1984, 1986; Nespor e Vogel, 1986) e da abordagem autossegmental-métrica da 
Fonologia Entoacional (Beckman; Pierrehumbert, 1986; Ladd, 1996, 2008; entre outros). Fazemos também uma breve revisão dos trabalhos que exploraram a relação entre estrutura prosódica e estrutura entoacional em $\mathrm{PB}$, dando destaque aos estudos realizados na variedade brasileira que investigam e/ou exploram a relevância de PW para a distribuição tonal: Fernandes (2007ab), Tenani e Fernandes-Svartman (2008), Vigário e Fernandes-Svartman (2010), Toneli, Vigário e Abaurre (2013, 2014), Toneli (2014) e Fernandes-Svartman e Romano (2017). Convém destacar que, como o presente trabalho dialoga com o de Toneli (2014) e com o de Fernandes-Svartman e Romano (2017), a revisão será feita ao longo de todo o texto.

\subsection{Fonologia Prosódica}

Na proposta de Nespor e Vogel (1986), a estrutura fonológica a partir do nível da palavra mantém relação estreita com a sintaxe, sendo organizada em constituintes prosódicos que são universais, de acordo com princípios apenas fonológicos, no caso dos constituintes mais baixos da hierarquia, e de acordo com informação morfológica, sintática e/ou semântica e fonológica, no caso dos constituintes do nível da palavra e superiores. Tais constituintes prosódicos, indicados em (1), estão organizados hierarquicamente e servem de domínio para a aplicação de regras fonológicas específicas (Selkirk, 1982, 1984, 1986; Nespor e Vogel, 1986).

(1)

$$
\begin{aligned}
& \text { U - Enunciado fonológico (Phonological Utterance) } \\
& \text { I - Sintagma entoacional (Intonational Phrase) } \\
& \phi \text { - Sintagma fonológico (Phonological Phrase) } \\
& \text { C - Grupo Clítico (Clitic Group) } \\
& \omega \text { - Palavra fonológica (Phonological Word) } \\
& \text { S - Pé (Foot) } \\
& \sigma \text { - Sílaba (Syllable) }
\end{aligned}
$$

Visto que nossa análise focará a distribuição de PAs em PW, sintetizaremos aspectos relacionados a tal domínio e ao constituinte imediatamente superior.

De acordo com Nespor e Vogel (1986), PW é um domínio do nível da palavra morfossintática. Contudo, a sua definição nas línguas apresenta alguma variação, podendo corresponder a uma palavra sintática ou ser uma unidade mais pequena do que o átomo sintático. Nas línguas consideradas em Nespor e Vogel (1986), tipicamente uma PW é formada por pelo menos um radical e pode incluir sufixos e/ou prefixos. Para além disso, PW é portadora de acento, pelo que um afixo com acento independente, por exemplo, pode formar uma PW autônoma. Nesta fase do modelo, por exigências internas à própria teoria, entretanto abandonadas, os clíticos fonológicos, embora não sendo portadores de acento independente, formavam também PW autônomas.

\footnotetext{
2 Neste texto, consideramos que domínio intermediário entre $\phi$ e PW é PWG, conforme proposta de Vigário (2007, 2010).

${ }^{3}$ Usamos os termos 'Palavra Fonológica' e 'Palavra Prosódica' como sinônimos.
} 
Como vimos, para o nosso estudo, para além do nível de PW, importa também crucialmente o domínio imediatamente superior, situado entre PW e $\phi$. Nos trabalhos primordiais em fonologia prosódica, foi proposto um constituinte desse nível antes de mais com vista a dar conta de fenômenos fonológicos envolvendo clíticos fonológicos e seus hospedeiros, daí a designação deste constituinte como Clitic Group (Nespor e Vogel, 1986). Contudo, vários estudos posteriores mostraram que os clíticos se ligam de modos distintos a constituintes de diferentes níveis da hierarquia prosódica, indiciando que a organização prosódica que envolve clíticos e hospedeiros não corresponde a um constituinte específico único. Por outro lado, foi também notado na literatura que palavras compostas e outras palavras sintáticas contendo duas ou mais palavras prosódicas desencadeiam frequentemente um comportamento fonológico diferente do que caracteriza combinações de palavras sintáticas. O fato de esses agrupamentos de palavras formarem um domínio acima de PW e abaixo de $\phi$ justifica, de modo independente da cliticização, a existência de um constituinte desse nível. Entretanto, dada a sua motivação preponderante não envolver de fato clíticos, foi proposta a alteração do nome do constituinte relevante para Composite Group (CG) ou Prosodic Word Group (PWG) - ver referências e argumentação defendendo este nível da estrutura prosódica em Vigário (2007, 2010). SegundoVigário (2007, 2010), o PWG corresponde no essencial a uma cabeça sintática (como julga, alegremente, luso-brasileiro ou porta-óculos), tornando-se evidente a diferença entre PW e PWG quando PWG ramifica, isto é, integra duas ou mais PWs. No presente trabalho, seguindo a literatura recente sobre o assunto nos estudos sobre o Português, adotamos a designação PWG para este constituinte prosódico.

\subsection{Fonologia Entoacional e trabalhos sobre PB desenvolvidos a partir dessa perspectiva teórica}

De acordo com a abordagem autossegmental-métrica da Fonologia Entoacional, conforme proposta de Pierrehumbert (1980), Pierrehumbert e Beckman (1986), Ladd (1992, 1996, 2008) e Frota (1998, 2000), a entoação tem uma organização fonológica própria e é observada em termos de frequência fundamental (F0), interpretada fonologicamente como uma sequência de eventos fonológicos discretos e não um contínuo caracterizado pela forma e pela direção (cf. Ladd, 1992; 2008). Tais eventos são categorizados em dois tipos: acentos tonais, formados pelos tons $\mathrm{L}$ (low) ou $\mathrm{H}$ (bigh), marcados com asterisco, indicando a sua associação com posições proeminentes, podendo ser simples/monotonais $\left(\mathrm{L}^{*}\right.$ ou $\left.\mathrm{H}^{*}\right)$ ou complexos (tipicamente bitonais, como $\mathrm{H}^{*}+\mathrm{L}, \mathrm{H}+\mathrm{L}^{*}, \mathrm{~L}^{*}+\mathrm{H}$ ou $\left.\mathrm{L}+\mathrm{H}^{*}\right)$; e tons de fronteira, marcados pelos tons $\mathrm{L}$ ou $\mathrm{H}$ (ou combinações destes tons) seguidos por diacrítico $\%$ no caso de fronteira de I ou U, ou acentos frasais, marcados por $\mathrm{H}$ - e L- e associados aos limites de um domínio prosódico mais baixo que I.

Já em relação aos trabalhos sobre a estrutura entoacional do PB, Tenani (2002) e Fernandes (2007), analisando a variedade paulista, observam que no PB, em posição inicial de I, ocorre preferencialmente um contorno ascendente, marcado pelos PAs $\mathrm{L}+\mathrm{H}^{*} / \mathrm{L}^{*}+\mathrm{H}$, associados à primeira sílaba acentuada de $\mathrm{I}$, independentemente de essa sílaba ser a mais proeminente do primeiro $\phi$ de I. Também é notada na literatura a ocorrência de um evento tonal inicial de PW quando há uma distância superior a três sílabas entre o início de PW e a primeira sílaba acentuada no PB (Frota e Vigário, 2000; Tenani, 2002; Fernandes, 2007a, 
2007b; Tenani e Fernandes-Svartman, 2008; Vigário e Fernandes-Svartman, 2010; Toneli, 2014; Frota et al., 2015; Fernandes-Svartman e Romano, 2017).

Tais estudos mostram ainda que a informação entoacional fornece pistas sobre domínios prosódicos como PW, $\phi$ e I no PB, sendo estes domínios relevantes para as regras de atribuição tonal. Destaca-se que, mesmo que as PWs não cabeças de $\phi$ s internos possam receber opcionalmente PA, há uma alta incidência de PA nessas posições. Nesse sentido, Fernandes (2007) afirma que o fato de haver PAs associadas a (quase) todas as PWs não cabeças de $\phi$ pode indicar a relevância do domínio PW para a distribuição tonal no PB. Em estudos subsequentes a esse, Tenani e Fernandes-Svartman (2008), Toneli, Vigário e Abaurre (2013; 2014), Toneli (2014) e Fernandes-Svartman e Romano (2017) têm defendido a relevância de PW para a distribuição tonal em contexto neutro, enquanto Vigário e Fernandes-Svartman (2010) mostram que o domínio mínimo de associação tonal obrigatória é PWG com forte incidência de PA associado à PW não cabeça de PWG, dependendo do tamanho ou da distância entre acentos tonais no interior de PWG.

Toneli (2014) argumenta com base no resultado dos testes estatísticos realizados que, independentemente do tipo de PWG - ramificado e não ramificado que estiver em posição interna de I, a probabilidade de ocorrer um PA por PW é maior do que a de ocorrer PA apenas nas cabeças de $\phi$ no PB e que a associação de um acento adicional de PW ocorre desde que haja distância mínima de três sílabas pretônicas em relação ao acento primário, o que é evidência da relevância do número de sílabas na atribuição tonal. Já Fernandes-Svartman e Romano (2017) mostram que há diferenças entre a associação de PAs às PWs que compõem o sujeito em relação aos PAs associados às PWs que compõem o predicado, pois, na primeira situação, a associação tonal a cada PW é praticamente categórica enquanto nos predicados é possível a associação de PA apenas à PW cabeça de $\phi$. De modo geral, os dois trabalhos mostram que há uma alta densidade tonal ${ }^{4}$ em sentenças neutras, pois há praticamente um PA por PW nas variedades do PB analisadas.

O presente trabalho ampliará a base empírica já investigada, mostrando que na variedade falada no Triângulo mineiro o número de sílabas em PW é fator preponderante para a alta densidade tonal em sentenças neutras, o que sugere a relevância de PW para a distribuição tonal, e que o domínio obrigatório é $\mathrm{PW}(\mathrm{G})$, aspecto já observado para a variedade paulista, estudada por Fernandes (2007), Tenani e Fernandes-Svartman (2008), Vigário e Fernandes-Svartman (2010) e Fernandes-Svartman e Romano (2017).

\section{CORPUS E METODOLOGIA DE OBTENÇÃo DOS DADOS E DE ANÁLISE}

Nesta seção, descrevemos o corpus utilizado para nossa análise, que inclui sentenças produzidas em contexto neutro (foco de escopo amplo), as quais são

\footnotetext{
${ }^{4}$ Também Frota et al. (2015) mostram uma alta densidade tonal em quatro variedades de PB - Porto Alegre, São Paulo, Belo Horizonte e Salvador -, não só em declarativas neutras, mas também em sentenças declarativas produzidas em contexto de foco estreito, sentenças interrogativas parciais e totais, sentenças que indicam ordens, pedidos e vocativos (chamamento e insistente). Ver mais informações sobre o projeto Interactive Atlas of the Prosody Portugueses (InAPoP) na página: http://www.fl.ul.pt/LaboratorioFonetica/InAPoP.
} 
formadas por sujeito, verbo e dois sintagmas pós-verbais - um logo após o verbo e o outro coincidindo com a fronteira de I, como apresentado em 2 -, sendo o sintagma pós-verbal construído com palavras morfologicamente simples, derivadas ou compostas (e.g. Araraquara, parlamentaristas e luso-brasileiros), duas palavras sintáticas (e.g. onze elefantes), ou uma palavra funcional seguida por uma palavra lexical (e.g. a responsabilidade).

É importante destacar que as palavras lexicais em análise vão variar em relação ao número de sílabas, contudo estão sempre na mesma posição sintática linear, ou seja, fazem parte do sintagma verbal e estão sempre imediatamente após o verbo, em interior de sentença - ver exemplos em 2 .

Durante a elaboração do corpus experimental, foram consideradas as seguintes variáveis:

(i) o contexto em que o foco é eliciado, no caso o de foco amplo;

(ii) o tipo e a quantidade de palavra(s) morfológica(s) que será/serão comparada(s) - palavra funcional + palavra lexical (uma única PW - PWG não ramificado), uma palavra composta por duas PWs (PWG ramificado) e duas PWs independentes que formavam dois PWGs não ramificados e um $\phi$ ramificado;

(iii) o número de sílabas pretônicas em relação à fronteira esquerda de cada palavra lexical;

(iv) a posição das palavras-alvo na sentença - imediatamente após o verbo, em interior de sentença, a fim de evitar influências das fronteiras de I;

(v) a estrutura sintática fixa (aqui entendida como ordenação linear dos constituintes): sujeito (clítico $+\mathrm{PW})+$ verbo $(\mathrm{PW})+$ palavra(s)-alvo + sintagma final (clítico + PW)

As sentenças a seguir em 2 exemplificam os dados do corpus.

a. As bolivianas gostavam [das jabutiCAbas] da fazenda.

b. Os estudantes encontraram [uma borboLEta] na janela.

c. Os empresários demonstraram [responsabiliDAde] nos negócios.

d. Os estudantes encontraram [LUso-brasiLEIros] no aeroporto.

e. Os americanos encontraram [ONze eleFANtes] no safári.

O corpus é constituído por 80 sentenças no total: 18 sentenças incluíam a sequência palavra funcional monossilábica ${ }^{6}+$ palavra lexical, como exemplificado em 2.a; 30 sentenças incluíam a sequência palavra funcional dissilábica ${ }^{7}+$ palavra lexical, como exemplificado em 2.b; 12 sentenças incluíam uma única palavra lexical, como exemplificado em 2.c; 10 sentenças incluíam uma palavra composta formada por duas PWs, como exemplificado em 2.d; e 10 sentenças incluíam a sequência de duas PWs independentes que formam um $\phi$ ramificado, como exemplificado em 2.e.

\footnotetext{
5 Controlamos o tamanho dos sintagmas na posição sujeito e na posição pós-verbal no final da sentença para que tivessem sempre tamanhos proporcionais em número de sílabas (de quatro a seis sílabas) e a mesma configuração prosódica (palavra funcional monossilábica e palavra lexical).

${ }^{6}$ Palavras funcionais monossilábicas analisadas: $o(s), a$, um, de, das, dos, por, na, no.

${ }^{7}$ Palavras funcionais dissilábicas analisadas: uma, sob, pelo(s), pela(s), para, contra, entre, sobre,
} 
Primeiramente o investigador explicava o procedimento experimental às informantes que, em seguida, participavam de uma fase treino para que $o$ investigador verificasse se elas haviam compreendido a tarefa. Na sequência, iniciavase a fase teste que consistia em uma tarefa de leitura silenciosa de uma sentença contexto projetada na tela do computador, e três segundos depois ouviam uma pergunta nos fones de ouvido, dando uma resposta apropriada, utilizando a informação apresentada na tela.

Esperava-se que as informantes produzissem a mesma sentença que haviam lido na tela do computador de modo mais próximo a uma situação real de interação.

Procedimento experimental para obtenção de sentenças em foco largo:

Sentença projetada na tela do computador:

Os caçadores encontraram um hipopótamo na floresta.

Pergunta ouvida pela informante:

Eu não ouvi o que você disse. O que aconteceu?

Resposta alvo:

Os cacadores encontraram um hipopótamo na floresta.

As gravações foram feitas em uma sala silenciosa no Instituto de Ciências e Tecnologias Exatas da Universidade Federal do Triângulo Mineiro. Para a gravação, foram utilizados um computador portátil, um gravador digital portátil, modelo Microtrack da M- Audio (mono, fonte de input $1 / 4$ TRS e taxa de amostragem 44.1) e um microfone de cabeça headset DPA, modelo d:fine omni com MicroDot (frequência $\pm 2 \mathrm{~dB}, 20 \mathrm{~Hz}-20 \mathrm{kHz}$ ). Foram gravadas três informantes de sexo feminino, com idade entre 18 e 30 anos, com nível universitário e residentes na cidade de Uberaba, Minas Gerais. A tarefa foi dividida em duas etapas que foram realizadas em dias diferentes. Para cada sentença, foram feitas três repetições totalizando 720 produções (80 sentenças x 3 informantes x 3 repetições). As sentenças foram distribuídas aleatoriamente em slides, e cada slide continha um único contexto para que fosse produzida uma única sentença. Tanto a segmentação das sentenças, que foram salvas em arquivos formato wav, quanto a análise foram feitas no programa Praat (Boersma e Weenink, 2012).

A análise engloba a transcrição ortográfica em palavras e a transcrição entoacional, indicadas em camadas pelo programa Praat - ver exemplos na próxima seção. Para a análise entoacional, seguimos a notação P-ToBI na abordagem autossegmental-métrica da Fonologia Entoacional, conforme adaptações para o português feitas por Frota (2000, 2009, 2015), Tenani (2002), Fernandes (2007) e Frota et al. (2015). Convém destacar que as sentenças são segmentadas apenas em palavras funcionais e lexicais e na linha abaixo há a marcação tonal dos PAs observados - ver exemplos na próxima seção.

Em relação à análise estatística a que os resultados foram submetidos, realizamos um teste de proporções múltiplas. Para isso, o valor de $\alpha$ foi ajustado ao número de arranjos, 2 a 2. Por exemplo, quando foi realizado um teste de hipótese em que são comparadas duas proporções quaisquer, o valor de $\alpha$ foi de 0,05 ; quando o teste de hipótese englobava várias proporções, o valor de $\alpha$ considerava o número dos arranjos analisados, por exemplo, para um arranjo de $5-2$ a 2 , o valor de $\alpha$ era 
de $0,0025=0,05$ dividido por 20. Para a análise dos resultados, foi considerado que a hipótese nula ( $\mathrm{H} 0)$ significava que os valores de $\mathrm{p}$ (os valores analisados) eram iguais, enquanto a hipótese alternativa (H1) considerava que os valores de $\mathrm{p}$ eram diferentes. Se $\mathrm{p}$ fosse maior do que o valor de significância (valor de $\alpha$ ), a hipótese H0 deveria ser aceita e H1 rejeitada, enquanto se $\mathrm{p}$ fosse menor do que o valor de significância, a hipótese $\mathrm{H} 0$ deveria ser rejeitada e a hipótese $\mathrm{H} 1$ aceita. Todos os testes estatísticos foram feitos no programa R, versão 3.0.2.

\section{DESCRIÇÃo E ANÁLISE DOS RESUlTADOS}

Como o experimento incluía sentenças que destoavam em relação à configuração interna após o verbo - ver 2 -, descreveremos os resultados obtidos para cada tipo separadamente e depois faremos uma comparação para mostrar que nossa hipótese é válida e confirma o que os trabalhos apresentados na seção 2 já afirmavam sobre a interação do domínio PW com a regra de distribuição tonal, já que o número de sílabas e a ramificação prosódica são também fatores preponderantes para a análise na linha do que defendem Frota e Vigário (2000), Vigário e FernandesSvartman (2010) e Fernandes-Svartman e Romano (2017). Com o intuito de manter uma uniformidade de análise e para controlar a influência de fronteiras de I, só mantivemos na análise as sentenças produzidas em um único I. Descrevemos também, além dos sintagmas alvo imediatamente posteriores ao verbo, os PAs associados à posição de sujeito na posição inicial de I e do sintagma adverbial na posição final para observar se a variedade mineira também é uma variedade de PB com alta densidade tonal, tal como aponta a literatura sobre a variedade paulista.

Começaremos nossa descrição apresentando as sentenças que incluíam palavras funcionais (monossilábicas e dissilábicas) seguidas de palavras lexicais que variavam de três a mais sílabas pretônicas (e.g. jabuticabas e borboletas) que formavam um PWG não ramificado na posição interna de I, ou seja, primeiro sintagma pósverbal - ver 2.a e 2.b. No total, foram analisadas 432 sentenças (48 sentenças x 3 informantes x 3 repetições). Nosso objetivo com tais sentenças era observar se ocorreria associação tonal nas palavras funcionais, além de PA associado à sílaba tônica da palavra lexical.

Primeiramente, descreveremos os dados obtidos para as sentenças que compunham no sintagma em análise a sequência palavra funcional monossilábica seguida de palavra lexical, como em Os professores discutiam a responsabilidade dos estudantes. Do total de 162 gravações obtidas para tais sentenças, 150 sentenças foram pronunciadas em um único I. Em relação à distribuição tonal no sintagma alvo, no caso o sintagma pós-verbal imediato, houve a atribuição de PA à PW que contém a palavra lexical (portadora da proeminência de PWG e de $\phi$ ) em 149 produções (99,33\%), como exemplificado pela Figura 1 com o PA $L^{*}+\mathrm{H}$ associado à sílaba tônica - da da palavra responsabilidade. 


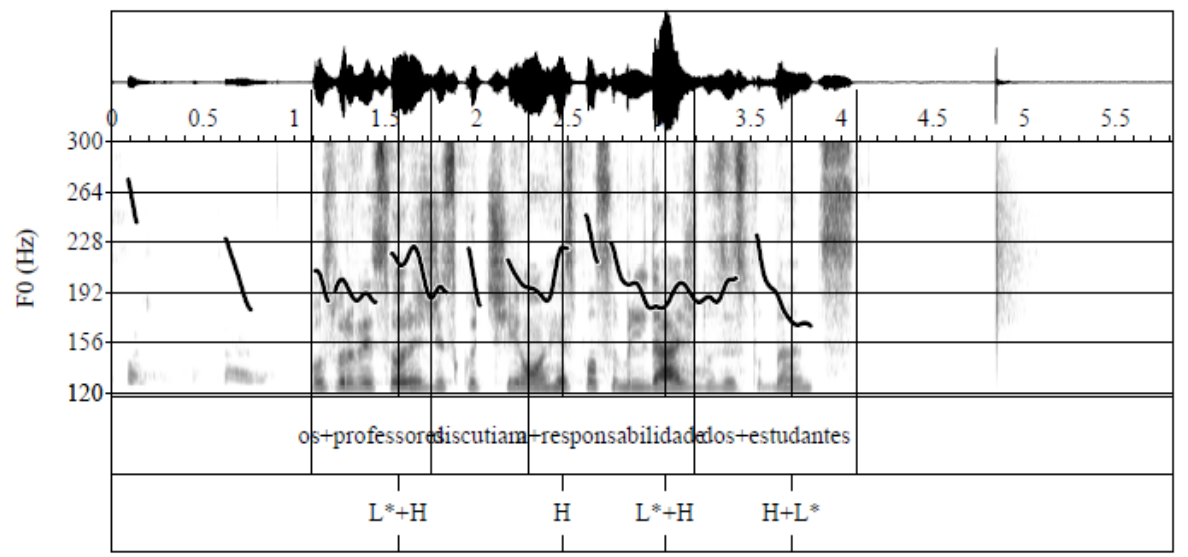

Figura 1 - Espectrograma da sentença produzida em contexto neutro Os professores discutiam a responsabilidade dos estudantes.

No exemplo apresentado pela Figura 1, podemos notar que, além de uma PA associado à sílaba tônica de responsabilidade, há um acento adicional $\mathrm{H}$ associado à primeira sílaba pretônica de PW, no caso na sílaba res- que está à esquerda da cabeça de PW e mantém a distância de cinco sílabas átonas em relação à tônica. Em relação ao conjunto de sentenças analisadas nessa condição, ocorreu associação de acento inicial nas sílabas pretônicas iniciais de palavra lexical em 20\% (30 sentenças) dos dados, preferencialmente em palavras que mantinham uma distância de pelo menos três sílabas pretônicas, sendo 13 sentenças com quatro pretônicas e 15 sentenças com cinco, como mostra a Figura 1. Esse fato corrobora a hipótese de que o número de sílabas pretônicas em PW é fator preponderante para a associação de um evento tonal adicional, fato também observado em trabalhos anteriores como Frota e Vigário (2000), Tenani (2002), Fernandes (2007), Vigário e Fernandes-Svartman (2010), Toneli (2014) e Fernandes-Svartman e Romano (2017), entre outros relativos ao PB. Por outro lado, não foi encontrado nenhum tipo de acento tonal alinhado às palavras funcionais monossilábicas, nem mesmo acento inicial de PW. Mesmo assim, notou-se uma alta densidade tonal nesse tipo de sentença, pois há praticamente um PA por PW da sentença, independente da posição em que se encontravam em I.

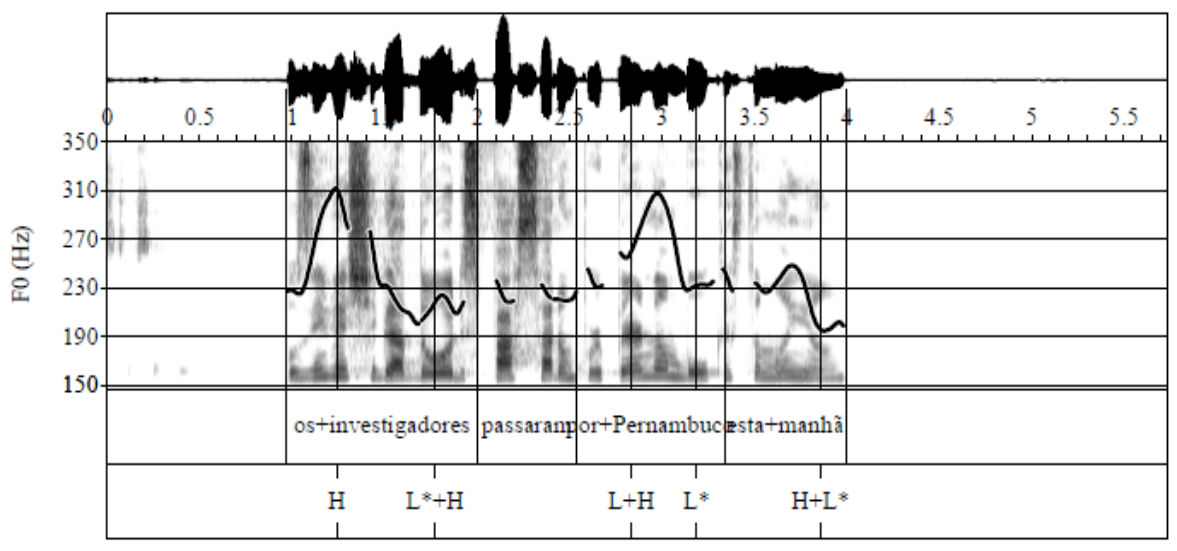

Figura 2 - Espectrograma da sentença produzida em contexto neutro Os investigadores passaram por Pernambuco esta manhã. 
Em relação às sílabas pretônicas imediatas, como em gambá, jacaré e restaurante, ocorreu uma marcação tonal mais enfática, como exemplificado na Figura $2^{8}$. Desse total, o acento enfático aparece associado à sílaba pretônica imediatamente precedente à tônica, como exemplificado pela Figura 2, na sílaba -nam, em Pernambuco. Aqui percebe-se que o tom $\mathrm{H}$ está alinhado à pretônica -nam enquanto o tom L está alinhado à sílaba Per. Destacamos que há poucos casos em que o acento enfático incidiu sobre a tônica e por isso não os contabilizamos aqui. Além disso, esses casos podem ser analisados como realizações enfáticas do PA associado à sílaba tônica e não um acento enfático independente. Esse dado então não se configura como uma evidência contrária à análise proposta de que o número de sílabas pretônicas é fator preponderante para a ocorrência de acento tonal adicional em PW.

A segunda sequência em análise é a que incluía palavras funcionais dissilábicas seguidas de palavra lexical - Os governadores chegaram sob tempestade esta manhã. No caso da preposição sob, ela foi considerada dissilábica, pois na variedade de PB analisada ela é sempre realizada com vogal epentética. Tais sentenças totalizaram 270 produções, sendo então 243 as sentenças mantidas para análise por terem sido as produzidas em um único $\mathrm{I}$.

A Figura 3 ilustra um exemplo em que tanto a palavra funcional dissilábica quanto a palavra lexical recebem PAs.

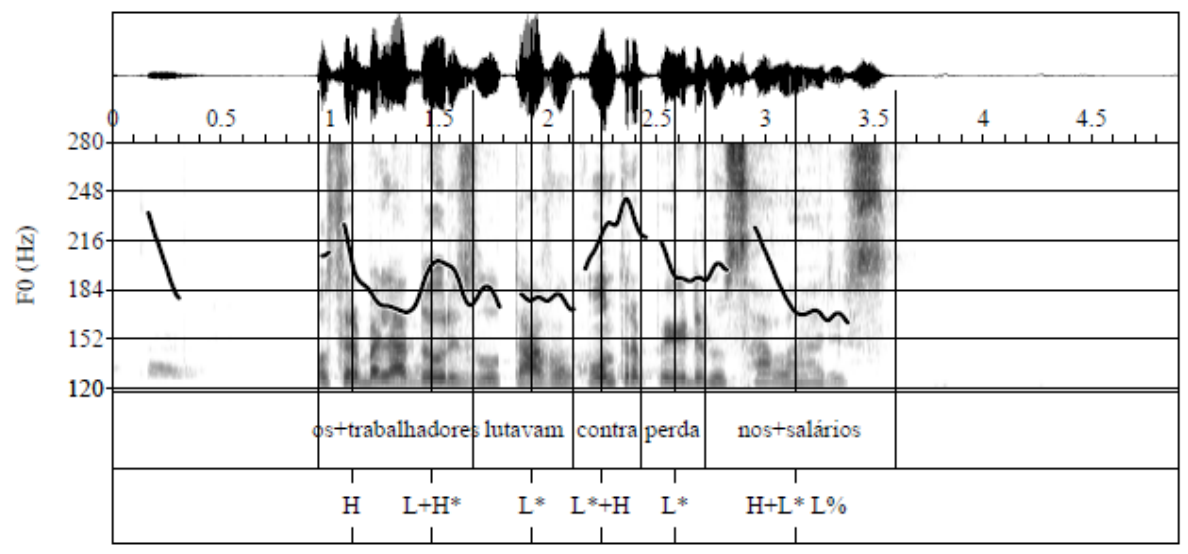

Figura 3 - Espectrograma da sentença produzida em contexto neutro Os trabalhadores lutavam contra perda nos salários.

A Tabela 1 apresenta a distribuição tonal dentro do $\phi$ formado pela palavra funcional dissilábica seguida pela palavra lexical, como exemplificado em 2.b, que também é PWG não ramificado.

\footnotetext{
8 Apesar de não ter sido observada a ocorrência de acento inicial associado a alguma sílaba pretônica imediata à tônica (quando a palavra tinha uma ou duas pretônicas), ocorreu uma marcação enfática semelhante ao que Vigário (2003), Toneli, Abaurre e Vigário (2014) e Toneli (2014) descrevem como acento enfático associado às sílabas pretônicas de PW em 18,5 \% das sentenças (28 sentenças), como exemplificado pela Figura 2. Essas autoras observaram que tal acento pode ser um evento bitonal $(\mathrm{L}+) \mathrm{H}$ com gama de variação estendida, marcada pela maior amplitude F0, embora o contorno ascendente pareça ser opcional, sendo caracterizado obrigatoriamente por um tom $\mathrm{H}$.
} 
Tabela 1 - Distribuição tonal no sintagma pós-verbal formado por palavra funcional dissilábica + palavra lexical.

\begin{tabular}{|c|c|c|}
\hline \multicolumn{2}{|c|}{$\begin{array}{c}\text { Associação tonal } \\
{[\text { func }+\operatorname{lex}] \phi}\end{array}$} & $M G^{9}$ \\
\hline$[-$ & - ] $\phi$ & $\begin{array}{l}1 \% \\
(2)\end{array}$ \\
\hline$[-$ & $\left.\mathrm{T}^{*}\right] \phi$ & $\begin{array}{c}90 \% \\
(218)\end{array}$ \\
\hline$\left[\mathrm{T}^{*}\right.$ & $\left.\mathrm{T}^{*}\right] \phi$ & $\begin{array}{c}9 \% \\
(23)\end{array}$ \\
\hline $\mathrm{p}-\mathrm{v}$ & alor & $<2,2 \mathrm{e}-16$ \\
\hline
\end{tabular}

Ao analisar os dados obtidos e apresentados na Tabela 1, vemos que há associação de PA à cabeça de PWG e do sintagma fonológico pós-verbal em 99\% dos enunciados, o que pode ser considerado uma associação categórica de PA à palavra lexical na posição interna de I que estamos analisando. É importante destacar que apenas em $9 \%$ dos enunciados tanto a palavra lexical quanto a palavra funcional dissilábica receberam PA. Entretanto, tal resultado não indica de todo que a associação tonal ocorre de modo categórico em relação à palavra funcional, principalmente quando comparamos o número de PAs associados à palavra lexical, em posição proeminente de $\phi(99 \%)$. Outro aspecto importante é que houve associação de PA à palavra funcional quanto a sentença incluía apenas as preposições contra, sobre e entre. Contudo não foi controlado o número de sílabas pretônicas da palavra lexical que seguia essas palavras funcionais para podermos levantar como hipótese que esse PA associado à palavra funcional é decorrente do número de sílabas da palavra lexical. Assim como nas sentenças com palavras funcionais monossilábicas, as palavras lexicais que seguem as palavras funcionais dissilábicas podem receber acento inicial de PW, apresentando o mesmo tipo de comportamento observado nos dados anteriores: associado às sílabas iniciais pretônicas à esquerda, mantendo uma distância mínima de três sílabas pretônicas em relação ao acento primário, tal como exemplificado também na Figura 2.

Nos casos em que ocorreu uma marcação tonal inicial de PW que não respeitava a distância de no mínimo três sílabas pretônicas, percebe-se a realização enfática nas sílabas pretônicas imediatas à sílaba tônica. A Figura 4 ilustra a realização de acento enfático associado à sílaba inicial tem- da palavra lexical tempestade em sentenças que incluem palavras funcionais dissilábicas.

${ }^{9}$ Sigla do estado ao qual pertence a variedade analisada. 


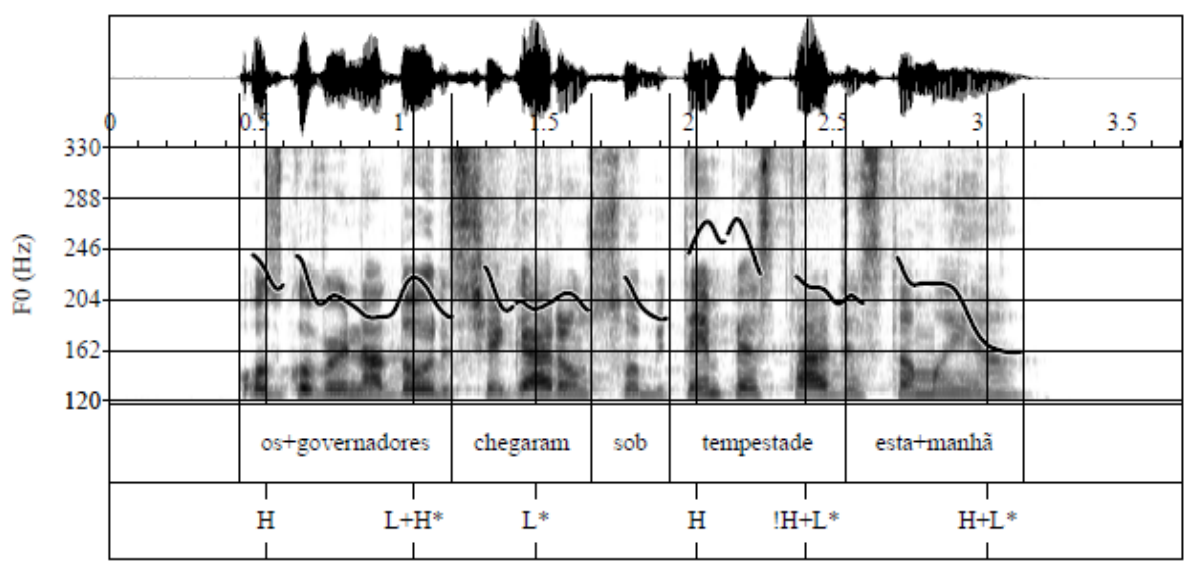

Figura 4 - Espectrograma da sentença produzida em contexto neutro Os governadores chegaram sob tempestade esta manhã.

Novamente foi observado o mesmo tipo de configuração tonal marcada pelo tom $\mathrm{H}$, sempre associado à palavra lexical e nunca associado à palavra funcional dissilábica. $\mathrm{O}$ fato de a funcional dissilábica nunca receber acento inicial ou acento enfático mostra que ela não se comporta prosodicamente como sílabas átonas da palavra lexical, o que evidencia que não formam juntamente com ela uma única PW que inclui a palavra lexical. Ademais a presença de tons iniciais nas sílabas pretônicas de palavras lexicais como tempestade quando antecedidas de palavra funcional fortificam essa análise de que o processo de prosodização da categoria funcional não se dá a nível de PW.

Em termos gerais, os resultados obtidos para as sentenças que incluem as palavras funcionais analisadas mostram que essas palavras não recebem acento tonal. Isso sugere que as palavras analisadas são clíticos fonológicos, na linha do proposto por Bisol $(2000,2005)$ em relação a algumas destas palavras com base em argumentos de natureza segmental. A relevância do estatuto prosódico das palavras vai tornar-se mais clara quando compararmos a incidência de PA nas sequências envolvendo palavra funcional e palavra lexical com a incidência de PA em PWG que ramificam.

A terceira situação em análise é a exemplificada em 2.c, que engloba as sentenças com uma única palavra lexical que constitui uma única PW e um PWG não ramificado - Os resultados mostravam insustentabilidade na economia. No total, foram produzidos 108 enunciados, mas 96 delas foram analisadas por terem sido produzidas em um único I. Destacamos que foi considerada a distribuição tonal para o verbo, que constitui uma PW independente e um PWG não ramificado, para posterior comparação com todas as sequências pós-verbais em análise $e^{10}$.

Dos resultados obtidos, em $95 \%$ das sentenças há a atribuição de PA tanto ao verbo quanto à palavra lexical seguinte e apenas em $5 \%$ somente a palavra lexical que segue o verbo recebeu $\mathrm{PA}$, sempre associado à cabeça de $\phi$, ou seja, há associação de PA à cabeça da palavra lexical pós-verbal em 100\% das sentenças analisadas (96 sentenças) - ver Tabela 2. Também ocorreu acento inicial de PW associado às sílabas

10 Como pretendíamos observar a relevância de PW para a distribuição tonal e para podermos comparar com as outras sequências internas de I, nesta situação de uma única palavra lexical ocorrer na posição pós-verbal, incluiremos na descrição a distribuição tonal associada ao verbo. 
iniciais das palavras lexicais em análise em 37,5\% das sentenças (36 sentenças de um total de 96), sendo dentre elas três ocorrências ( $3 \%$ do total) de acento enfático nas sílabas pretônicas de PW quando esta equivalia à palavra lexical pós-verbal.

A Figura 5 exemplifica um caso em que há PA associado à cabeça de $\phi$ e um acento enfático associado às sílabas iniciais de PW.

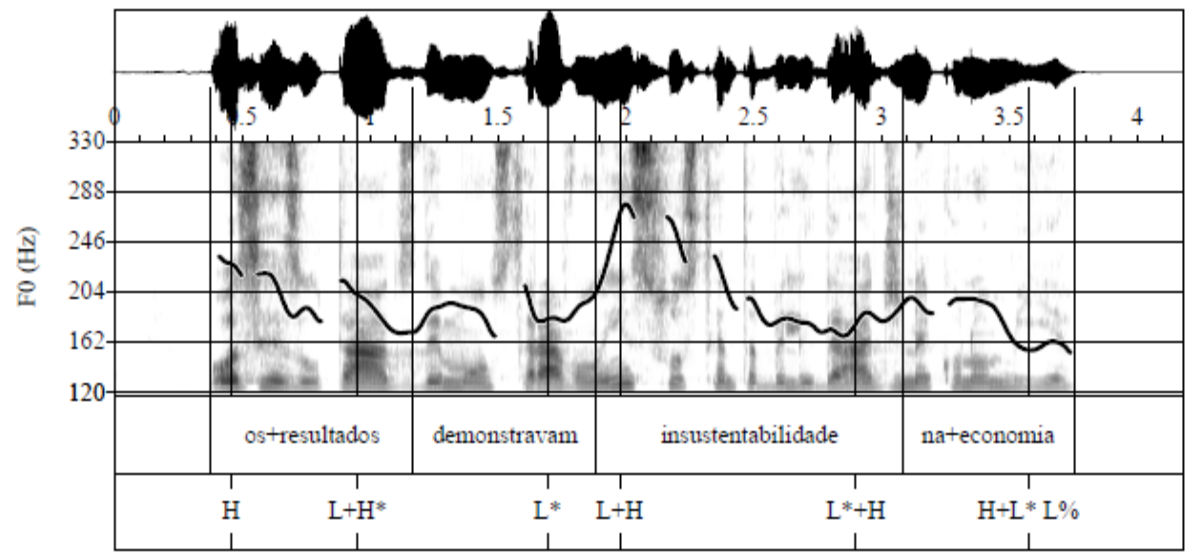

Figura 5 - Espectrograma da sentença produzida em contexto neutro Os resultados demonstravam insustentabilidade na economia.

$\mathrm{Na}$ Tabela 2, apresentamos a distribuição tonal para o tipo de sentença analisado. Nesta tabela, são somados os resultados de acento enfático e acento inicial de PW na quarta linha.

Tabela 2 - Distribuição tonal no sintagma verbal formado por um verbo e no sintagma pósverbal formado por uma única palavra lexical

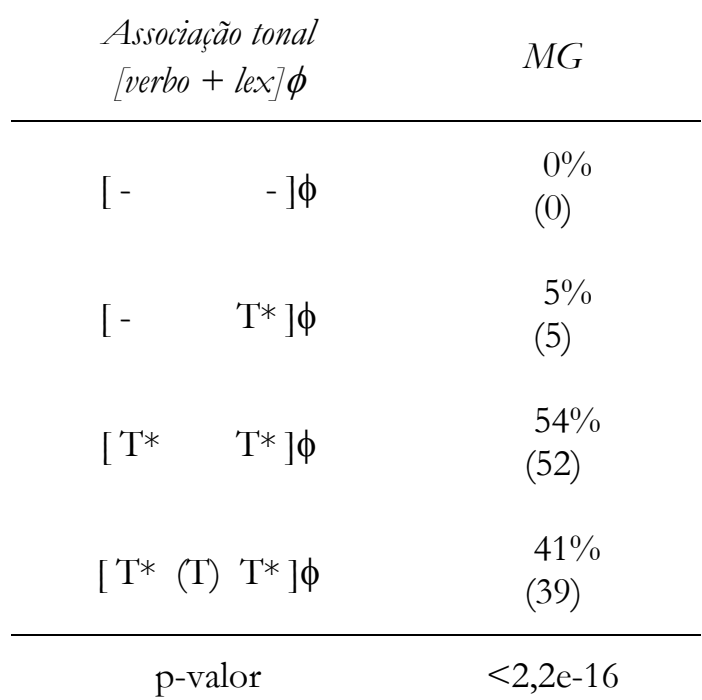

Novamente, para validar nossa análise, realizamos o teste de proporções múltiplas para verificar se a probabilidade de ocorrer um PA por PW interna em I é significante (nesse caso estamos considerando o verbo e o sintagma pós-verbal imediato), já que há associação categórica de PA à PW pós-verbal. No entanto, o 
teste de hipótese aplicado, considerando um nível de significância 0,004166, para um arranjo 4 de 2 a 2, mostra-nos que a hipótese $\mathrm{H} 0$ deve ser rejeitada, já que as proporções não são todas iguais.

$\mathrm{Na}$ sequência, analisamos qual das proporções, considerando os pares de valores, se sobrepõe às demais. Ao compararmos as proporções em que há PA associado a cada PW da sequência verbo + palavra lexical (91/96) - terceira e quarta linhas da Tabela 2 - em oposição à proporção de ocorrer PA apenas na palavra lexical (5/ 96) - segunda linha, o resultado do teste é de <2.2e-16. O teste de proporções em pares nos mostra novamente que a hipótese $\mathrm{H} 0$ deve ser rejeitada, pois a probabilidade de ocorrer PA associado a cada PW da sequência é estatisticamente maior do que a proporção de ocorrer PA apenas na palavra lexical pós-verbal em análise. Essa comparação mostra a relevância de $\mathrm{PW}(\mathrm{G})$ para a distribuição tonal, embora não indique se o domínio obrigatório para a distribuição tonal é PW ou PWG, pois ainda há coincidência entre PW e PWG não ramificado, no caso do verbo e do sintagma pós-verbal. O contexto descrito de seguida será mais esclarecedor a este respeito.

A quarta situação a ser analisada é a que inclui sentenças com uma palavra lexical composta morfologicamente formada por duas PWs independentes. Para esta configuração, foram obtidas 90 sentenças, contudo a análise inclui 80 delas, pois estas foram produzidas em um único I como no exemplo Os venezuelanos encontraram lusorevolucionários no congresso - ver Figura 6. Na Figura ilustrada, observa-se que há PA L* associado à sílaba tônica do verbo encontraram e na sequência notam-se PAs associados a cada PW da palavra lexical, um $\mathrm{L}^{*}+\mathrm{H}$ associado à sílaba tônica de luso e outro $\mathrm{H}+\mathrm{L}^{*}$ associado à sílaba tônica de revolucionário. Há ainda um tom $\mathrm{H}$ alinhado à primeira sílaba pretônica à esquerda $r e$ -

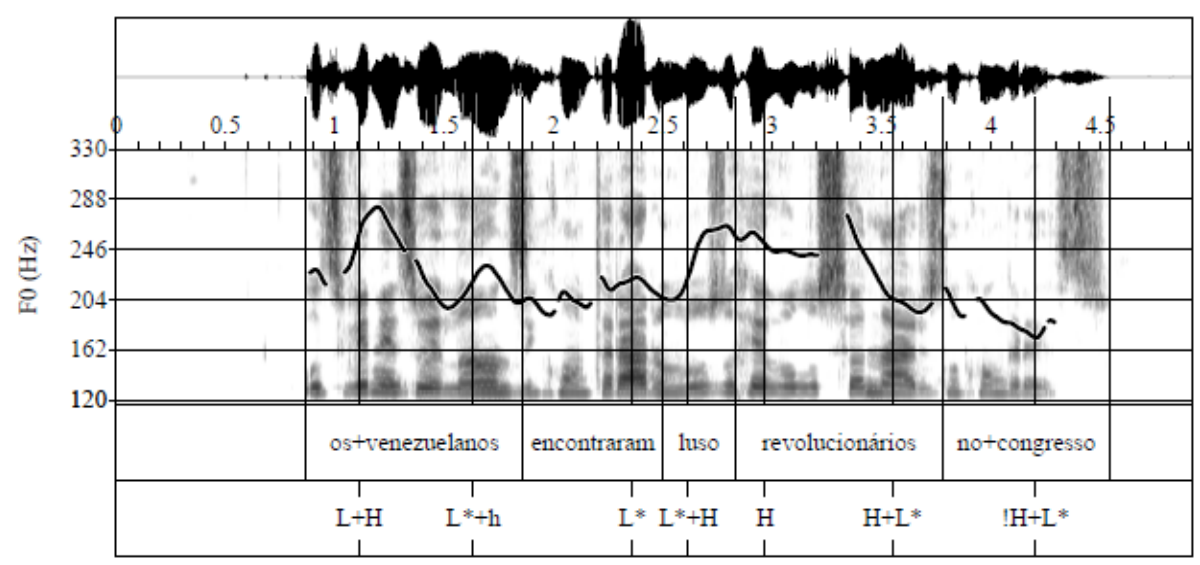

Figura 6 - Espectrograma da sentença produzida em contexto neutro Os venezuelanos encontraram luso-revolucionários no congresso.

$\mathrm{Na}$ Tabela 3, apresentamos a distribuição tonal para as PWs internas de I desde o verbo até o sintagma pós-verbal imediato. 
Tabela 3 - Distribuição tonal no sintagma pós-verbal formado por palavra lexical formada por duas PWs.

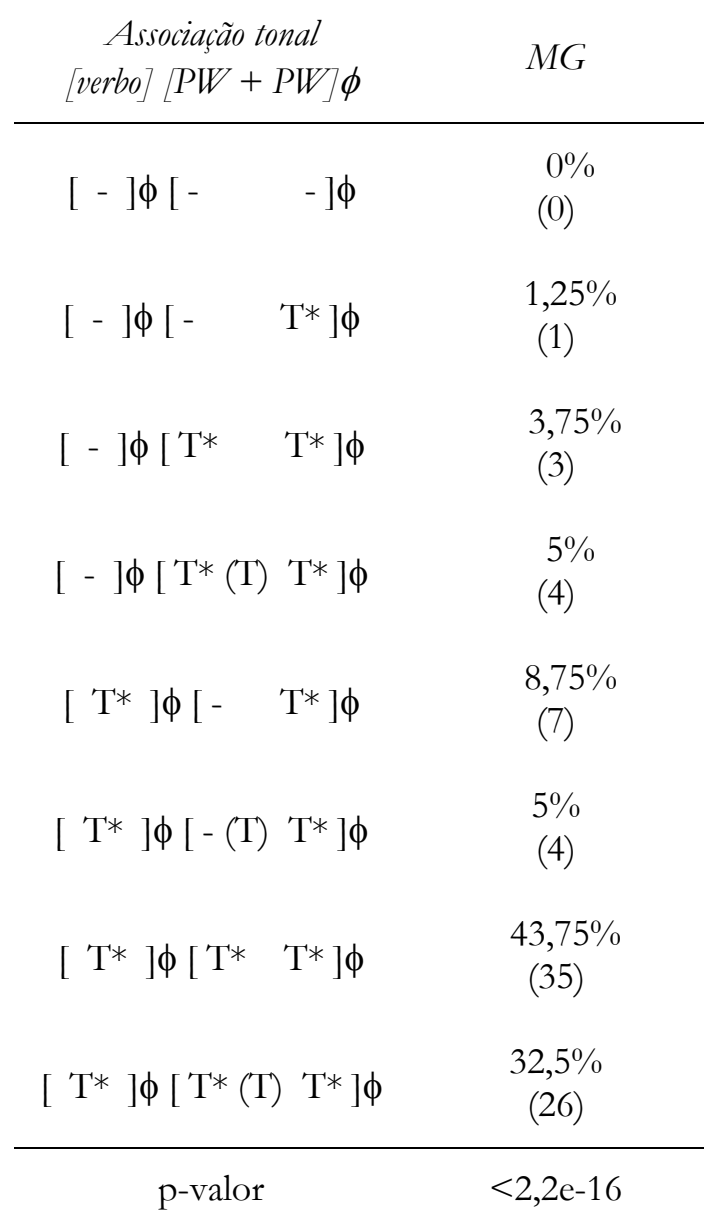

Como pode ser observado na Tabela 3, dos resultados obtidos, em 76,25\% das sentenças (61 sentenças) há a atribuição de PA tanto ao verbo quanto às duas PWs que compõem a palavra lexical. Em $85 \%$ dos enunciados há um PA em cada PW do sintagma pós-verbal (65 sentenças - e.g. luso-revolucionário), enquanto um PA associado à cabeça do $\phi$ que contém o verbo ocorreu em $90 \%$ das sentenças ( 72 sentenças). O que pode ser percebido é que há um pouco mais de PA associados a essa posição do que à PW não cabeça de PWG ramificado.

Também ocorreu acento inicial de PW associado às sílabas iniciais da PW mais à direita - revolucionário - de PWG ramificado em 42,5\% das sentenças (34 sentenças), uma vez que a PW cabeça de PWG ramificado da palavra composta possuía um número maior de sílabas pretônicas - até cinco sílabas - em comparação à PW não cabeça (e.g. micropaleontologia vs civiliz̧adamente) com até três sílabas pretônicas. Assim como nos dados discutidos anteriormente, o acento inicial mantém uma distância mínima de duas sílabas átonas em relação ao acento primário - ver Figura 6. Desses 42,5\% das sentenças (34 sentenças), observou-se que quanto maior o número de sílabas pretônicas, maior a probabilidade de um acento adicional, desde que a PW possuísse três ou mais sílabas pretônicas. 
Em relação ao acento enfático, só foram notadas três ocorrências $(3 \%$ do total) de acento enfático nas sílabas pretônicas de PW mais à direita - ver Figura 6 . Também foi notada associação de acento enfático na sílaba tônica de PW não cabeça de PWG ramificado em 47,5\% (38 sentenças) e apenas 5\% na PW cabeça de PWG ramificado (4 sentenças). Tais dados não foram discriminados separadamente na Tabela 3.

Para validar a significância de tais resultados, aplicamos o teste de proporções múltiplas e avaliamos novamente a probabilidade de ocorrer um PA por PW na posição pós-verbal em I em oposição à possibilidade de ocorrer PA associado apenas à $\mathrm{PW}$ que equivalia ao verbo. $\mathrm{O}$ teste de hipótese nos mostra novamente que a hipótese H0 deve ser rejeitada, considerando um nível de significância 0,00893 , para um arranjo 8 de 2 a 2 . O valor de p apresentado na Tabela 3 é menor do que o nível de significância, evidenciando que as proporções são diferentes, ou seja, a probabilidade de ocorrer um PA por PW na posição interna de I é estatisticamente maior.

Assim, para analisarmos quais dessas proporções se sobrepõem às demais, passamos a comparar as proporções em pares. Quando comparamos a possibilidade de ocorrer um PA por cada PW (61/ 80) - que incluía o verbo e o sintagma subsequente - em oposição à possibilidade de ocorrer PA apenas nas cabeças de PWG (19/ 80) - excluindo a PW não cabeça de PWG ramificado (e.g. luso), o resultado do teste é 9.011e-11, novamente menor que o nível de significância 0,05 . Esse teste de proporções em pares nos mostra que a probabilidade de ocorrer um PA por PW interna de I na posição pós-verbal é estatisticamente maior do que ocorrer PA apenas na cabeça de PWG ramificado ${ }^{11}$.

Em síntese, ao comparar a probabilidade de ocorrer PA nos outros pares, todos os testes mostram que a probabilidade de ocorrer um PA por PW interna de I é alta, principalmente quando se compara com a possibilidade de ocorrer PA associado a cada PW de PWG ramificado. Tais dados respaldam a análise da relevância de PW para a distribuição tonal e também a alta densidade tonal das PWs, em torno de $85 \%$ dos enunciados de PA por PW em I. Sobretudo é importante ressaltar que por haver coincidência entre PW e PWG não ramificado, no caso do verbo e dos sintagmas pós-verbais exemplificados em $2 \mathrm{a}, 2 \mathrm{~b}, 2 \mathrm{c}$ e $2 \mathrm{e}$, não podemos afirmar categoricamente que o domínio obrigatório para a associação tonal não é PWG, ficando essa investigação a ser feita futuramente.

Por fim, descrevemos os resultados obtidos para as sentenças que incluíam duas palavras lexicais que constituem PWG não ramificado cada (e.g. vinte republicanos) e estão diretamente ligadas a $\phi$, visto que, diferentemente da situação anterior, não formam uma palavra composta morfologicamente, mas são palavras lexicais independentes, como exemplificado em 2.e. De um total de 90 sentenças obtidas, nossa análise inclui 87 delas por terem sido produzidas em um único I, como no exemplo Os estudantes encontraram vinte republicanos no parlamento - ver Figura 7.

11 Como o experimento não controlou um número proporcional de sentenças com poucas sílabas pretônicas na PW cabeça de PWG ramificado, é preciso expandir o corpus para afirmarmos que o número de sílabas dessa PW interfere na ocorrência de PA na PW não cabeça, o que fortificaria a afirmação de que é PWG e não PW o domínio obrigatório para a distribuição tonal. Essa questão fica aberta para trabalhos futuros. 


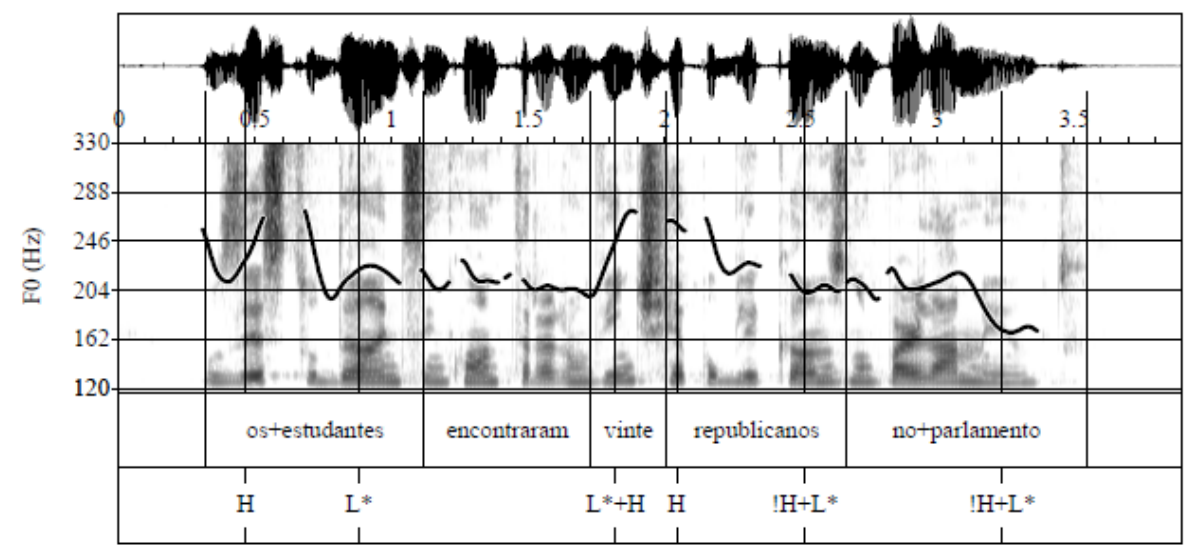

Figura 7 - Espectrograma da sentença produzida em contexto neutro Os estudantes encontraram vinte republicanos no parlamento.

A Figura 7 exemplifica um caso em que há associação tonal nas duas PWs do sintagma pós-verbal, mas não há no verbo. Nesse caso, todas as PWs também constituem PWGs não ramificados.

$\mathrm{Na}$ Tabela 4, apresentamos a distribuição tonal para as PWs internas após o verbo, destacando que há também a notação da associação tonal ao verbo.

Tabela 4 - Distribuição tonal no sintagma pós-verbal formado por duas palavras lexicais.

\begin{tabular}{|c|c|}
\hline $\begin{array}{c}\text { Associação tonal } \\
{[\text { verbo] }[P W+P W] \phi}\end{array}$ & $M G$ \\
\hline$[-] \phi[-$ & $\begin{array}{l}0 \% \\
(0)\end{array}$ \\
\hline$[-] \phi\left[-\quad(\mathrm{T}) \mathrm{T}^{*}\right] \phi$ & $\begin{array}{l}1 \% \\
\text { (1) }\end{array}$ \\
\hline$[-] \phi\left[\begin{array}{cc}\mathrm{T}^{*} & \mathrm{~T}^{*}\end{array}\right] \phi$ & $\begin{array}{l}14 \% \\
(12)\end{array}$ \\
\hline$[-] \phi\left[\mathrm{T}^{*}(\mathrm{~T}) \mathrm{T}^{*}\right] \phi$ & $\begin{array}{l}5 \% \\
(4)\end{array}$ \\
\hline$\left[\begin{array}{c}\mathrm{T}^{*}\end{array}\right] \phi\left[-\mathrm{T}^{*}\right] \phi$ & $\begin{array}{l}0 \% \\
(0)\end{array}$ \\
\hline 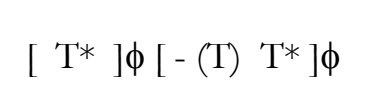 & $\begin{array}{l}1 \% \\
(1)\end{array}$ \\
\hline$\left[\begin{array}{c}\mathrm{T}^{*}\end{array}\right] \phi\left[\begin{array}{cc}\mathrm{T}^{*} & \mathrm{~T}^{*}\end{array}\right] \phi$ & $\begin{array}{l}53 \% \\
(46)\end{array}$ \\
\hline$\left[\mathrm{T}^{*}\right] \phi\left[\mathrm{T}^{*}(\mathrm{~T}) \mathrm{T}^{*}\right] \phi$ & $\begin{array}{l}26 \% \\
(23)\end{array}$ \\
\hline p-valor & $2,2 \mathrm{e}-16$ \\
\hline
\end{tabular}


Conforme mostra a Tabela 4, em 98\% dos dados a associação tonal ao PWG não cabeça do sintagma pós-verbal (85 sentenças), enquanto a cabeça do $\phi$ que inclui o verbo recebe PA em apenas $80 \%$ das sentenças (70 sentenças). Isso mostra que a posição pós-verbal parece ser mais proeminente que o verbo propriamente dito ${ }^{12}$.

Assim como nas outras situações analisadas anteriormente, houve atribuição (i) de acento inicial de PW em 32\% das produções (28 sentenças) quando a PW mais à direita tinha mais que duas sílabas pretônicas - ver Figura 7 -, (ii) de acento enfático associado à sílaba inicial da PW cabeça de $\phi$ (1\% das sentenças), ou ao PWG cabeça de $\phi$ ( $3 \%$ das sentenças) ou ao PWG não cabeça de $\phi(20 \%$ das sentenças). Tais resultados do acento enfático não estão discriminados separadamente na Tabela 4.

Para reforçar mais uma vez nossa análise, aplicamos o teste de proporções múltiplas para avaliar a probabilidade de ocorrer um PA por PW(G) interna em I. Tal teste de hipótese mostra que o valor de $\mathrm{p}$ é menor do que o nível de significância (0,00893), ou seja, as proporções analisadas não são todas iguais. Como há associação categórica de PA ao PWG cabeça de $\phi$ em 100\% das sentenças (e.g. republicanos) e praticamente categórica ao PWG não cabeça de $\phi$ em $98 \%$ das sentenças (e.g. vinte), passamos a compará-las em pares para testarmos qual dessas proporções se sobrepõe às demais. Quando comparamos a proporção de ocorrer um PA por cada $\mathrm{PW}(\mathrm{G}) \mathrm{em}$ $\mathrm{I}(69 / 87)$ em oposição à proporção de ocorrer PA apenas no $\mathrm{PW}(\mathrm{G})$ mais à direita (e.g. republicanos), o teste de proporções em pares nos mostra que o valor de $\mathrm{p}$ $(=3.43 \mathrm{e}-14)$ é menor que o nível de significância 0,00893 , o que mostra que a proporção de ocorrer um PA por PW(G) é estatisticamente maior.

Em suma, antes de passarmos à comparação das cinco situações analisadas e exemplificadas em 2 e pelas Figuras 1-7, mostramos que a variedade mineira analisada é uma variedade de $\mathrm{PB}$ com alta densidade tonal, visto que a probabilidade de ocorrer PA associado ao PWG que inclui o verbo e a cada PW(G) do sintagma seguinte em posição interna de I é estatisticamente maior do que ocorrer PA apenas em cabeças de $\phi$ e I. Em nossa análise, o número de sílabas mostrou ser relevante para tal resultado, visto que quanto maior a quantidade de sílabas em PW que estão em posição interna de I, maior a probabilidade de ocorrência de eventos tonais adicionais em início de PW. Nesse sentido, nosso estudo dialoga com os estudos anteriores sobre a variedade paulista ao mostrar a alta densidade tonal de outra variedade de $\mathrm{PB}$ e a associação tonal praticamente obrigatória em $\mathrm{PW}(\mathrm{G}) \mathrm{s}$ de I, principalmente em relação às PWs internas de $\mathrm{I}^{13}$.

Descrito o comportamento entoacional dos cinco tipos de sintagmas pósverbais e imediatos ao verbo, passamos agora à comparação entre o comportamento entoacional das sequências em análise: (i) palavra funcional monossilábica + palavra lexical (PWG não ramificado); (ii) palavra funcional dissilábica + palavra lexical (PWG não ramificado); (iii) palavra lexical sozinha (PWG não ramificado); (iv)

\footnotetext{
12 Uma hipótese a ser investigada futuramente é se há proeminência do predicado quando composto por dois sintagmas pós-verbais para comparar com o estudo de Fernandes-Svartman e Romano (2017) sobre a posição sujeito, controlando o tamanho do verbo em número de sílabas para posterior análise.

${ }^{13}$ Como o corpus não foi elaborado para observar ramificação sintática em nenhuma posição de I, deixamos essa comparação para trabalhos futuros, para ser comparado com o estudo de FernandesSvartman e Romano (2017).
} 
palavra lexical composta por dois radicais acentuados (PWG ramificado); (v) duas palavras lexicais (dois PWGs não ramificados). Nosso objetivo com essa comparação é mostrar a relevância de PW para a distribuição tonal na variedade mineira para além de PWG, uma vez que em algumas dessas sequências PWs e PWG não ramificado coincidem. Posteriormente, aproximaremos nossos resultados para a variedade mineira com os resultados de Fernandes-Svartman e Romano (2017) para a variedade paulista.

A primeira comparação é da sequência palavra funcional monossilábica + palavra lexical, como em a responsabiliD Ade (ver também 2.a), com uma única PW que é uma palavra lexical, como em agramaticaliD Ade (ver também 2.c), ambas com seis sílabas pretônicas, incluindo a palavra funcional átona do primeiro caso. Nos dois casos, notamos que as cabeças do sintagma fonológico pós-verbal, como as exemplificadas acima, recebem PA associado à sílaba tônica da PW (que é também o elemento proeminente de PWG e de $\phi$ ) e acento inicial associado às sílabas pretônicas iniciais, primeira ou segunda sílaba à esquerda, mantendo a distância mínima de três sílabas pretônicas em relação ao acento primário, e não foi observado nem acento inicial nem PA associado à palavra funcional. Em relação à distribuição tonal, o que esses resultados mostram é que uma palavra funcional monossilábica não recebe PA tal como uma palavra lexical, o que parece ser evidência de que apenas palavras morfológicas que formam PW podem receber PA.

Por outro lado, quando comparamos (i) a sequência palavra funcional dissilábica + palavra lexical, como em ENtre parlamentaRIStas (2.b), em relação (ii) a uma palavra composta por duas PWs, como em LUso-revolucioNÁrios (2.d), e (iii) a duas $\mathrm{PW}(\mathrm{G})$ que formam um $\phi$ ramificado, como em VINte republiCAnos (2.e), notamos que o comportamento entoacional é parcialmente semelhante: há um PA associado à sílaba tônica da PW cabeça do PWG e de $\phi$, de modo praticamente categórico, enquanto que apenas nos dois últimos casos, (ii) e (iii), há uma elevada presença de PA na não cabeça. No entanto, no interior de PWG (condição ii) a incidência de PW à não cabeça é opcional (85\%), enquanto no interior de $\phi$ (condição iii) o PWG não-cabeça recebe sempre PA (98\%). É comum a todas as condições, (i)-(iii), a possibilidade de acento inicial associado às sílabas pretônicas iniciais da PW cabeça de PWG e de $\phi$ quando a PW tem mais que duas sílabas pretônicas. Sobretudo em relação a (i), isto é, nos casos com palavra funcional dissilábica + palavra lexical, há algumas diferenças que se salientam: a ocorrência de PA associado à sílaba (eventualmente) tônica da palavra funcional é rara.

Com base na comparação desses resultados, destacamos que, independente da configuração prosódica do sintagma pós-verbal, há atribuição categórica de PA à PW cabeça do domínio que ela compõe, seja PWG não ramificado, PWG ramificado ou $\phi$ ramificado. Somente quando analisamos os resultados de PAs associados às PWs de PWG ramificado em relação às demais é que confirmamos nossa hipótese inicial da relevância de PW para a distribuição tonal, além de também corroborar o papel do tamanho de palavra em número de sílabas pretônicas para a associação de PA adicionais (exemplos 2.b, 2.d e 2.e), como acento inicial de PW e PA à PW não cabeça de PWG ramificado, visto que quanto maior o número de sílabas de domínio PW, maior é a probabilidade de eventos tonais. É importante reforçar ainda que os resultados obtidos, devido à coincidência entre PW e PWG não ramificado em várias das condições analisadas, não permitem afirmar que não é PWG o domínio de 
atribuição tonal obrigatória, mas sim a relevância não só de PWG como também de PW para as regras de atribuição de acentos tonais. Em qualquer caso, tal distribuição de acentos tonais na variedade mineira resulta numa alta densidade tonal em sentenças neutras, tal como observado em outras variedades do PB, em particular a variedade paulista.

\section{CONSIDERAÇÕES FINAIS}

O presente trabalho teve como objetivo analisar a distribuição tonal em sentenças produzidas em contexto de foco de escopo largo, sentenças consideradas neutras, em uma variedade de $\mathrm{PB}$, que é a variedade mineira falada no Triângulo Mineiro, com ênfase na análise das sequências internas de I, mais especificamente a sequência após o verbo, com o intuito de neutralizar a influência das fronteiras de I e de verificar se a densidade tonal é alta como já observada em outras variedades de PB - ver seção 2. Nossas hipóteses eram as de que o número de sílabas de PW e a configuração prosódica seriam fatores que poderiam influenciar a densidade tonal, além de que os domínio relevantes para a associação tonal seriam PWG e PW, uma vez que já eram esperados PAs associados às cabeças lexicais dos $\phi$ s em todas as posições da sentença, como demonstrado em trabalhos anteriores apresentados na seção 2 .

No geral, a análise confirmou tais hipóteses, corroborando o que os trabalhos anteriores sobre o PB já haviam mostrado em relação ao número de sílabas e à ramificação prosódica (cf. Frota e Vigário, 2000; Tenani, 2002, Fernandes, 2007; Vigário e Fernandes-Svartman, 2010; Toneli 2014; Fernandes-Svartman e Romano, 2017; entre outros), na medida em que foram encontradas diferenças entre a associação de PAs às PWs em PWG ramificado em comparação à associação de PAs à PW em PWG não ramificado dentro de $\phi$ s ramificados: em qualquer caso, nas cabeças de PWG a associação de PA é praticamente obrigatória, quer PWG seja cabeça de $\phi$, quer não; enquanto nas PW não cabeça de PWG parece ser opcional, embora muito frequente; neste último caso, mas não no primeiro, a atribuição de PA mostra-se potenciada pelo tamanho das PW que integram PWG.

Tal comparação foi validada pela análise estatística, que mostrou que o domínio de PW, e não apenas PWG, é relevante para a atribuição tonal. Além disso, os resultados mostraram que quanto maior o constituinte prosódico pós-verbal imediato ao verbo, maior foi a probabilidade de associação de evento tonal adicional em início de PW. A alta densidade tonal na posição pós-verbal independente da quantidade de PWs e da ramificação ou não de PWG e $\phi$ parece indicar uma proeminência dessa posição, talvez motivada por fatores sintáticos ou mesmo prosódicos, como o número de sílabas das PWs, visto que quanto maior o número de sílabas pretônicas maior a probabilidade de ocorrer um tom adicional em início de PW.

Esses resultados nos mostram também que, embora ocorra raramente, a palavra funcional dissilábica sofre um processo típico de palavras lexicais que são PW, que é a associação de um PA na sílaba tônica, o que pode ser considerada evidência do estatuto de PW de pelo menos algumas dessas palavras. Como já destacado anteriormente, somente três das palavras analisadas (e.g. contra, sobre e entre) receberam PA. Esse fato não pode sozinho ser evidência de que palavras funcionais 
dissilábicas como pelo(a)(s), sob e uma(s) possuam estatuto de palavras clíticas e não de PWs. Ressaltamos a necessidade de mais estudos em prol de verificar o estatuto prosódico dessas palavras funcionais em outras variedades do $\mathrm{PB}$, além da variedade mineira, tal como os realizados por Toneli $(2009,2014)$ para as variedades paulista e mineira e Vigário (2003) para o Português Europeu.

Por fim, com base nos resultados obtidos e nas análises apresentadas, algumas questões surgiram a serem exploradas em trabalhos futuros: 1 . O número de sílabas na palavra lexical influencia a realização enfática? 2. A língua diferencia o tipo de palavra funcional dissilábica que receberá PA? 3. A distância entre sílabas tônicas dentro de PWG ramificado é fator preponderante para a ocorrência de PA na PW não cabeça do domínio prosódico de que faz parte? 4. Um corpus que controlasse a composição e o tamanho do sujeito e do predicado com mais de um sintagma pósverbal tanto na variedade mineira do Triângulo Mineiro quanto de outras variedades de PB apresentariam resultados mostrando a proeminência da posição interna que não coincide com a fronteira final de I, como por nós mostrada, ou da posição sujeito, como mostrado por Fernandes-Svartman e Romano (2017) para a variedade paulista?

Fica assim claro que a identificação dos fatores que regulam a distribuição tonal na variedade mineira e também noutras variedades do PB carece de mais investigação, envolvendo recolha e análise de dados controlando, nomeadamente, as variáveis prosódicas e sintáticas identificadas acima, a qual ficará para pesquisas futuras.

\section{REFERÊNCIAS}

Abaurre MBM; Fernandes-Svartman FR. Secondary stress, vowel reduction and rhythmic implementation in Brazilian Portuguese. In: Bisol L; Brescancini CR, organizadoras. Contemporary Phonology in Brazil. Newcastle: Cambridge Scholars Publishing; 2008. p. 54-83.

Beckman M; Pierrehumbert J. Intonational structure in Japanese and English. Phonology Yearbook, 1986;3(1):255-309.

Bisol L. O clítico e seu status prosódico. Revista de Estudos da Linguagem. 2000;9(1):5-30.

Bisol L. Mattoso Câmara Jr. e a palavra prosódica. Delta. 2004;20(especial):59-70.

Bisol L. O clítico e seu hospedeiro. Letras de hoje. 2005;40(3):163-184.

Boersma P; Weenink D. Praat: doing phonetics by computer. [programa de computador]. Versão 5.2.07. Amsterdam: Universiteit van Amsterdam. [citado 24 dez. 2010]. Disponível em: http//: www.praat.org.

Fernandes FR. Ordem, focalização, e preenchimento em Português: sintaxe e prosódia. [tese]. Campinas, Instituto de Estudos da Linguagem, Universidade Estadual de Campinas; 2007.

Fernandes-Svartman FR. Acento secundário, atribuição tonal e ênfase em português brasileiro (PB). Estudos Lingüísticos. 2009;38:47-58.

Fernandes-Svartman FR; Romano N. Fatores determinantes na associação tonal em sentenças neutras do português brasileiro. Cadernos de Estudos Linguísticos. 2017;59(3):537-553. 
Frota S. Prosody and focus in European Portuguese: Phonological phrasing and intonation. New York: Garland Publishing; 2000.

Frota S; Cruz M; Fernandes-Svartman F; Collischonn G; Fonseca A; Serra C; Oliveira P; Vigário M. Intonational variation in Portuguese: European and Brazilian varieties. In: Frota S; Prieto P, editoras. Intonation in Romance. Oxford: Oxford University Press; 2015. p. 235-283.

Frota S; Vigário M. Aspectos de prosódia comparada: ritmo e entoação no PE e no PB. In: Castro R V; Barbosa P, organizadoras. Actas do XV Encontro Nacional da Associação Portuguesa de Linguística. Coimbra: APL; 2000. v.1. p. 533-555.

Hayes B. The prosodic hierarchy in meter. In: Kiparsky P; Youmans G. Phonetics and Phonology Rhythm and Meter. San Diego, California: Academic Press; 1989. Vol. 1. p. 201-260.

Hayes B; Lahiri A. Bengali intonational phonology. Natural Language \& Linguistic Theory. 1991;9(1):47-96.

Ladd DR. Intonational Phonology. Cambridge: Cambridge University Press; 1996.

Leiria LL. Em busca da palavra prosódica. [tese]. Porto Alegre, Pontifícia Universidade Católica do Rio Grande do Sul; 2000.

Nespor M; Vogel I. Prosodic Phonology. Dordrecht: Foris Publications; 1986.

Nespor M; Vogel I. Prosodic phonology: With a new foreword. Berlin/New York: Mouton de Gruyter; 2007.

Pierrehumbert J. The phonology and phonetics of English intonation. [tese]. Cambridge, Mass., Massachusetts Institute of Technology; 1980.

Selkirk EO. Phonology and Syntax: The Relation between Sound and Structure. Cambridge: The MIT Press; 1984.

Selkirk EO. On derived domains in sentence phonology. Phonology Yearbook, 1986;3:371-405.

Selkirk EO. The interaction of constraints on prosodic phrasing. In: Horne M, editor. Prosody: Theory and Experiment. Netherlands: Kluwer Academic Publishers; 2000. p. 231-261.

Tenani LE. Domínios prosódicos no Português. [tese]. Campinas, Instituto de Estudos da Linguagem, Universidade Estadual de Campinas; 2002.

Tenani L; Fernandes-Svartman FR. Prosodic phrasing and intonation in neutral and subject-narrowfocus sentences of Brazilian Portuguese. Proceedings of Fourth Conference on Speech Prosody 2008. Campinas: RG/CNPq; 2008. p. 445-448.

Toneli PM. A palavra prosódica no Português Brasileiro: o estatuto prosódico das palavras funcionais. [dissertação]. Campinas, Instituto de Estudos da Linguagem, Universidade Estadual de Campinas; 2009.

Toneli PM. A palavra prosódica no Português Brasileiro. [tese]. Campinas, Instituto de Estudos da Linguagem, Universidade Estadual de Campinas; 2014.

Toneli PM; Vigário M; Abaurre MBM. Distinguishing emphatic and prosodic word inital stresses: evidences from Brazilian Portuguese. In: Proceedings of the 4th International Symposium on Tonal Aspects of Languages, Nijmegen; 2014.

Vigário M. Prosodic structure between the prosodic word and the phonological phrase: recursive nodes or an independent domain? The Linguistic Review. 2010;27(4)-485-530. 
Vigário M. O lugar do Grupo Clítico e da Palavra Prosódica Composta na hierarquia prosódica: uma nova proposta. In: Lobo M; Coutinho MA, organizadoras. Actas do XXII Encontro Nacional da Associação Portuguesa de Lingüística: Textos seleccionados. Lisboa: Colibri Artes Gráficas; 2007. p. 673-688.

Vigário M. The prosodic word in European Portuguese. Berlin/New York: Mouton de Gruyter; 2003.

Vigário M. The prosodic status of stressless function words in European Portuguese. In: Hall TA; Kleinhenz U, editores. Studies on the phonological word. Current Issues in Linguistic Theory, vol. 174. Amsterdam/ Philadelphia: John Benjamins; 1999.

Vigário M; Fernandes-Svartman FR. A atribuição de acentos tonais em compostos no português do Brasil. In: Brito AM; Silva F; Veloso J; Fiéis A, organizadoras. XXV Encontro da Associação Portuguesa de Lingǘstica - Textos Seleccionados. Porto: Tip. Nunes; 2010. Vol. 1. p. 769-786. 